\title{
Foreword \\ by The Duke of Argyll
}

Only very occasionally, if at all, do all the right ingredients come together naturally to form the ideal recipe in whatever field. I would liken it to the socalled 'Primeval Soup' from which all life on Earth sprang. To this day we do not know if anything like it exists in the entire Cosmos, but these conditions have been met by the author. Others, with a profound thirst in the subject, realised what an opportunity there lay to produce this, a comprehensive history of the Clan of which I happen to be the extremely proud Chief, and to this end they prevailed on Alastair Campbell of Airds to undertake the mammoth task of which this is the first of an expected three volumes.

Here we have a man who has painstakingly collated and gleaned the knowledge with an enthusiasm for the subject that has since his youth seen him gathering small bits of a vast jigsaw. From his first few decades he kept meticulous notebooks, for no particular purpose other than his own pleasure, and these were to prove invaluable in this work of heroic magnitude.

The author has drawn together a myriad of strands, which in themselves took lifetimes to complete by extremely able historians in their own right.

People and manuscripts as well as authenticated stories from all five continents of the globe have been carefully scrutinised to build up the vast wealth of information which these books will contain.

I am delighted to commend this work to kinsmen and scholars alike, as well as to all who hold a special place for Scotland and all its peoples in their souls.

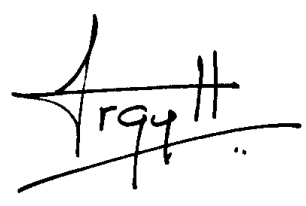

